DOI: $10.17805 /$ zpu.2017.1.13

\title{
Восточноазиатская интеграция в сфере международного туризма
}

\author{
В. И. БАЛАКИН \\ МОСКОВСКИЙ ГУМАНИТАРНЫЙ УНИВЕРСИТЕТ
}

Международный туризм как форма региональной интеграции занимает специфическое место в многочисленных исследовательских проектах, анализирующих сложные процессы современного общественного развития. Это в полной мере относится к Восточноазиатскому региону, где диалектика взаимоотношений местных государств имеет весьма сложное историческое наследие. Специалисты рассматривают международный туризм в Восточной Азии в качестве весьма серьезного интегрирующего фактора, способствующего эффективному преодолению застарелых региональных противоречий. В статье предпринята попытка показать реальное состояние и перспективы развития восточноазиатского интеграционного пространства, в том числе в сфере международного туризма. Восточноазиатский рынок туристических услуг является одним из самых конкурентных в мире. Его отличительной особенностью выступает то, что он задает тренды, которые затем проявляются уже на глобальном уровне. Практически все государства Восточной Азии преимущественно делают ставку на внутренний и въездной виды туризма, развивая таким образом национальную инфраструктуру и заметно пополняя местные бюджеты. Внутренний туризм базируется на посещении исторических мест, памятников древней культуры, на паломнических миссиях, связанных с религиозными традициями, тогда как въездной туризм иностранцев ориентирован прежде всего на получение недорогих высококвалифицированных медицинских услуг в рамках программ проведения комплексной диагностики и лечения сложных заболеваний.

В КНР весьма рассчитывают через объединение региональных суверенных государств создать общую туриндустрию, которая бы способствовала внедрению в сознание широких народных масс идеи единой конфуцианской цивилизации. В последнее время китайские власти на всех уровнях стали пропагандировать так называемую интернационализа- 
цию, понимая ее исключительно как восточноазиатский региональный проект и противопоставляя его западной концепции глобализма.

Восточноазиатский туризм отображает природное и культурное многообразие стран региона, их экономические достижения, стремление сохранить тысячелетнее наследие. Именно туризм стал в регионе важным каналом ознакомления с достижениями человеческого духа, уважения человеческих достоинств и индивидуальности, признания самобытности культур и моральных ценностей восточноазиатских наций. Восточноазиатский туризм стимулирует образование и научную деятельность, что позволяет философски осмыслить сущность регионального культурного наследия и перспективы его дальнейшего развития.

Ключевые слова: Восточная Азия; интеграция; международный туризм; региональные противоречия; зарубежные китайские общины

\section{ВВЕАЕНИЕ}

$\mathrm{M}$ ногие исследователи полагают, что туризм в странах Восточной Азии имеет свою особую философию. В реальности восточноазиатская концепция туризма выступает в виде мировоззрения и своеобразного культурного феномена, отражающего неразрывную связь человека с окружающей средой, а также новые гуманитарные взгляды на уже, казалось бы, изученные области знаний. В российской исследовательской литературе практически нет описания названного явления, поскольку по объективным причинам, главной из которых выступает отсутствие мощных турпотоков из России в страны Восточной Азии, трудно глубоко изучать то, чего нет. Вместе с тем в аккумулированном виде не всегда получается найти по данной теме и комплексные зарубежные исследования, так как сфера восточноазиатского внутреннего и въездного туризма не представляет собой тему, которая могла бы привлечь к себе серьезное внимание прежде всего в США и Евросоюзе.

В этой связи целью настоящей статьи является некий анализ опыта восточноазиатских государств по формированию регионального международного рынка туристических услуг, что может представить практический интерес для активно развивающейся туриндустрии в России.

\section{МЕЖАУНАРОАНЫЙ ТУРИЗМ В ВОСТОЧНОАЗИАТСКОМ РЕГИОНЕ}

Развивающиеся процессы восточноазиатской интеграции объективно способствуют последовательному сближению и более тесному сотрудничеству восточноазиатских государств. Несмотря на отдельные, иногда даже весьма серьезные, противоречия, последовательно формируется устойчивое региональное туристическое сообщество. Уже сегодня видны примечательные тенденции к созданию на уровне региона единого туристического пространства, определению общих стандартов функционирования индустрии международного сервиса, а также учреждению многонациональных холдингов в сфере внутрирегионального туризма. Интернациональным становится менеджмент в рамках восточноазиатской туриндустрии, что делает ее достаточно профессиональной, а значит, более конкурентоспособной на местных рынках в соперничестве с крупными западными корпорациями. Очевидные успехи турбизнеса Восточной Азии стимулируют наиболее видных его представителей к выходу на глобальный рынок и побуждают к установлению эффективного контроля над туристическими потоками в восточноазиатские страны из других регионов мира (Zhang, 2014: 161).

Существует объективная диалектика устойчивого становления восточноазиатской интеграции в сфере туризма. Заметное значение получает стимул развивать эффек- 
тивный бизнес, опираясь на объективное наличие естественных различий традиционных культур, местных обычаев, привычек, географических особенностей и социальных предпочтений. Весьма последовательно вызревает диалектический феномен единства и борьбы противоположностей, в рамках которого региональная интеграция выступает как исключение, ибо диалектика всегда проявляется в деталях. В этом смысле реальная действительность Восточной Азии постоянно эволюционирует и выносит на поверхность развития объективные конфликты восточноазиатских государств, стремящихся выйти за рамки тысячелетнего китайского культурного доминирования. Названное общее ощущение иногда порождает попытки самоутверждения, даже иногда жесткого отрицания сложившихся традиций, но постепенно все возвращается на круги своя и китайский цивилизационный фактор все равно берет свое, меняя лишь форму воздействия (Sawada, 2014: 16).

Культурное доминирование Китая в Восточной Азии, его «мягкая сила», представляет собой основополагающий фактор, на котором строится диалектика региональной интеграции, в том числе и в области туризма, - иными словами, наблюдается постоянная борьба внутри восточноазиатского сообщества относительно того, с каким знаком воспринимать китайский региональный вызов.

КНР определяет главный тренд взаимодействия государств Восточной Азии на туристическом направлении, что в первую очередь касается максимального упрощения визовых и таможенных процедур, особенно в развитии туризма в культурной, медицинской и спортивной сферах. Китай выступает в качестве инициатора разработки комплексных программ по подготовке эффективных специалистов для формирующейся региональной инфраструктуры туризма, включая отельный, ресторанный и экскурсоводческий бизнес. В 2014 г. кратно возросло число туристических обменов между тремя ведущими государствами Восточной Азии: КНР, Японией и Республикой Корея (26 млн человек), которые, несмотря на наличие серьезных политических разногласий, активно стимулируют взаимные посещения (Chen, Mak, McKercher, 2011: 120-136). В 2015-2016 гг., по данным Мирового банка, количество посещений увеличилось в полтора раза (World Bank, 2015 \2016: 13). Заметно расширились региональные фестивальные программы, привлекающие огромное количество туристов, их популярность объясняется многолетним ежегодным проведением и этническим своеобразием. Кроме того, фестивали и традиционные праздники формируют мощные туристические потоки в противоположных направлениях, когда южане едут в северные страны региона, где проводятся снежные фестивали (Харбин, Саппоро), а северяне посещают теплые морские курорты на юге (Хайнань, Бали), чтобы насладиться солнечной погодой.

\section{ХАРАКТЕРИСТИКА ВОСТОЧНОАЗИАТСКОГО ТУРИСТИЧЕСКОГО РЫНКА}

Международный туризм в Восточной Азии весьма активно поддерживается правительствами всех региональных государств. Согласовываются национальные туристические программы, в которых особое внимание уделяется выработке единых критериев качества туристических услуг, включая их сертификацию (Iwate, 2014: 77). Аидерами восточноазиатской интеграции в туриндустрии выступают Китай, Япония и Республика Корея. Три государства уже договорились о создании унифицированного режима предоставления туристических услуг, оставив при этом за собой неотъемлемое право сохранять высочайший уровень конкуренции. Тем не менее присутствует объективная проблема визового режима, которая делает китайский рынок более 
конкурентоспособным, чем в других восточноазиатских странах, за счет количественных показателей ежегодного роста.

Восточноазиатский рынок туристических услуг является одним из самых конкурентных в мире, и при этом его отличительной особенностью выступает то, что он во многом задает тренды, которые затем в значительной степени проявляются уже на глобальном уровне (Hoshino, 2014: 13-14). Так, практически все государства Восточной Азии преимущественно делают ставку на внутренний и въездной виды туризма, развивая таким образом национальную инфраструктуру и заметно пополняя местные бюджеты. Внутренний туризм, как правило, базируется на посещении исторических мест, памятников древней культуры, на паломнических миссиях, связанных с религиозными традициями. Что касается въездного туризма иностранцев, то здесь безусловный и неоспоримый приоритет всегда отдается получению высококвалифицированных медицинских услуг в рамках программ комплексной диагностики и лечения сложных заболеваний. Выездной туризм в государствах Восточной Азии в основном связан с теми и иными культурными и спортивными событиями за рубежом.

По оценкам соответствующих правительственных ведомств, внутренний и въездной туризм в значительной степени стал одним из основных финансовых источников формирования национальных бюджетов в странах Восточной Азии, особенно на местном уровне. Последовательно растет число туристов, приезжающих из США и Евросоюза, и темпы увеличения въездных турпотоков заметно опережают прирост туристических обменов внутри Восточноазиатского региона. В определенной степени последнее вызвано с визовыми ограничениями в отдельных странах Восточной Азии (Индонезия, Вьетнам, Малайзия, Филиппины, Таиланд и даже Япония) в отношении туристов из KНР, что связано с традиционными опасениями из-за активной политической работы Пекина с тамошними китайскими общинами. В сфере въездного туризма практически все восточноазиатские государства проявляют серьезную практическую заинтересованность к сотрудничеству с Российской Федерацией в туристической сфере, резонно полагая, что российские туристы, в отличие от китайских, никогда не будут преследовать никаких политических целей. На турпотоки из России претендуют практически все восточноазиатские страны, а это, с другой стороны, свидетельствует о значительном российском потенциале не только и не столько в области выездного туризма, сколько о формировании собственных въездных турпотоков из восточноазиатских стран, особенно на российский Аальний Восток (Vincent, 2014: 26).

При всем разнообразии видов туризма, практикуемого в Восточной Азии, несомненным лидером среди них является туризм, связанный с личным посещением и осмотром исторических достопримечательностей. В отличие от Европы восточноазиатские туристы и у себя в стране, и за рубежом нацелены на посещение какого-то одного памятника истории, и с этим приходится считаться принимающей стороне, если она рассчитывает привлечь к себе устойчивый турпоток. В данном случае логика и существующая практика показывают, что такой тур должен иметь продолжительность не менее семи дней и включать в себя продуманное содержание, ориентированное на позитивное восприятие и удовлетворение эстетических предпочтений посетителей, заинтересованных прежде всего в максимальном погружении в реальную атмосферу того или иного исторического события, а также связанных с ним сохранившихся артефактов. В связи с этим наиболее перспективным подобное региональное сотрудничество выглядит в рамках взаимоотношений России с такими соседними странами, как Китай, Япония и Республика Корея. Исторический событийный ряд между ними 
позволяет организовывать масштабные туристические обмены по многим достаточно редким направлениям (Nakayama, 2013: 22). Вместе с тем исторический туризм во многом подвержен политической конъюнктуре и всегда напрямую зависит от взаимоотношений государств в каждый конкретный период.

Именно политическая составляющая исторического туризма заставляет восточноазиатские страны пересматривать многие идеологические заблуждения, а при целенаправленной творческой работе с посетителями туристических объектов воспоминания об имевших место взаимоотношениях региональных государств и связанных с ними исторических событиях способны кардинально поменять сложившиеся ошибочные представления и побудить все заинтересованные страны перейти к постепенному интеграционному взаимодействию исключительно с учетом накопленного положительного опыта, а также пытаясь исправить совершенные ранее ошибки. Например, одну из таких геополитических ошибок Япония исправляет сегодня, организуя незаметный отход Монголии из-под влияния Москвы и Пекина, в результате чего монгольская территория по факту может оказаться стратегическим резервом японского государства на случай непредвиденных катастроф в тихоокеанской зоне. В значительной степени этому также способствовало японо-монгольское взаимодействие в экономике, включая «исторический туризм», когда Токио на основе некой «духовной близости двух народов» удалось создать свой собственный и весьма конкурентоспособный политический альянс с Улан-Батором на границах России и Китая, имеющий сегодня весьма непредсказуемую направленность (Nishida, 2014: 78). По многочисленным японским стратегическим оценкам, проигрывая в целом борьбу за региональное лидерство в Восточной Азии Китаю, Япония вполне способна создать Аля КНР определенные геополитические проблемы в ее отношениях с Тайванем, используя, кроме всего прочего, глубоко укоренившиеся туристические обмены с островным сообществом и опираясь при этом на значительную прояпонски настроенную часть местного населения. Монголия и Тайвань вполне могут оказаться существенными козырями в руках японской политической элиты, стремящейся не упустить своего последнего шанса и добиться значимой роли в рамках объективного процесса восточноазиатской интеграции.

В отличие, например, от Евросоюза региональная туриндустрия в Восточной Азии пока плохо структурирована и во многом весьма зависит от политических взаимоотношений между отдельно взятыми восточноазиатскими странами. Политические системы региональных государств часто различаются существенным образом, но при этом в Восточной Азии существует один важный интегрирующий фактор в виде влиятельных зарубежных китайских диаспор, которые уже многие столетия интегрированы между собой и осуществляют туристическую деятельность, основанную на глубоком осознании себя единой цивилизационной общностью (Chang-Hung, 2012: 70). Подобное этническое единение серьезно пугает правительства многих восточноазиатских государств, и не столько с экономической точки зрения, сколько из-за прошлого печального опыта захвата китайцами «командных высот» в этих странах и их последующего растущего политического влияния, способного напрямую воздействовать на местные государственные институты. Некоторые международные эксперты утверждают, что зарубежные китайские общины вполне способны эффективно противодействовать любым невыгодным для них инвестиционным проектам в странах Восточной Азии, реализуемым основными конкурентами КНР, т. е. японскими и южнокорейскими корпорациями. Пекинское руководство, работая с зарубежными ки- 
тайскими диаспорами, активно использует их для продвижения собственной модели восточноазиатской интеграции, в том числе в сфере регионального туризма.

\section{РЕГИОНААЬНЫЙ ТУРИЗМ В КАЧЕСТВЕ СИСТЕМНОГО ИНТЕГРАТОРА КИТАЯ В ВОСТОЧНОЙ АЗИИ}

Руководство КНР не стесняется реализовывать через зарубежные китайские общины новые идеи структурирования регионального туризма в Восточной Азии (Furuyi, 2014: 18). Выдвигая предложение о формировании восточноазиатского интеграционного сообщества, Пекин полагает, что наиболее перспективным направлением объединения региональных суверенных государств могло бы стать создание общей туриндустрии, которая внешне не отдавала бы предпочтения какому-либо государству, но одновременно закладывала бы в сознание широких народных масс идею единой цивилизации, разумеется конфуцианской. В последнее время совершенно осознанно китайские власти на всех уровнях стали пропагандировать так называемую интернационализацию, понимая ее исключительно как восточноазиатский региональный проект и противопоставляя тем самым западной концепции глобализма. Очевидно, сегодняшний Китай настойчиво продвигает в общества государств Восточной Азии модернизационную матрицу, сутью которой является адаптирование любого зарубежного опыта к местным реалиям. Зарубежные китайские общины рассматриваются в качестве важнейшего элемента внедрения названной матрицы в практическую жизнь, а главное - несущей мощный заряд сформулированной Пекином идеологии.

Идеологическую составляющую в развитии регионального международного туризма в Восточной Азии трудно не заметить, особенно когда анализируются программы путешествий, предлагаемые местными турагентствами. Обращает на себя особое внимание готовность Китая, Японии, Республики Корея, а также АCЕАН к тесной международной кооперации, о чем свидетельствует недавнее создание региональной федерации международного туризма, одной из функций деятельности которой стало одобренное практически всеми заинтересованными государствами расширение внутреннего и въездного туризма, ориентированного прежде всего на местных граждан. В учредительном акте о создании федерации было зафиксировано обязательство правительств заинтересованных государств снять до конца 2020 г. все политические барьеры на пути всестороннего общения рядовых граждан, а также изъять из рекламных туристических материалов информацию о сложных периодах взаимоотношений отдельных государств Восточной Азии. В рамках федерации предполагается разработать систему так называемых сквозных туров, которая позволяла бы осуществлять туристические поездки в рамках всего Восточноазиатского региона по единому правоустанавливающему документу. Унификация стандартов региональной туристической деятельности, по общему мнению экспертов, будет способствовать выстраиванию общего интегрированного пространства, побуждать местных предпринимателей расширять свой бизнес в масштабах всей Восточной Азии (Su-Hsin Lee, 2014: 28).

Таким образом, восточноазиатская интеграция в сфере международного туризма демонстрирует заметный прогресс на фоне в целом достаточно сложной обстановки в деле комплексного формирования единого экономического пространства на региональном уровне. Тем не менее в региональном международном туризме Восточной Азии заложен огромный потенциал для создания общего рынка малой и средней деловой активности, позволяющего значительно увеличить количество востребованных рабочих мест, постоянно пополнять местные бюджеты, до некоторой степени снимать 
напряженность в отношениях между государствами, имеющими застарелые исторические претензии друг к другу. Единение региона в такой поистине гуманной области межнационального взаимодействия, как туризм, выстраивает весьма позитивную обстановку для восточноазиатского экономического пространства, делая его исключительно конкурентоспособным в глазах авторитетных глобальных инвесторов. В данной связи Восточная Азия, как пишет Р. Шарплей, не может не развиваться как целостная территория, в рамках которой создана унифицированная инфраструктура с самым благоприятным инвестиционным климатом (Sharpley, 2012: 230). Широко известно, что для любого инвестора аксиомой является правило, гласящее: капиталовложения в инфраструктуру, пусть даже и социальную, всегда окупаются, если за бизнес-проектом в полной мере присутствует реально выраженная государственная заинтересованность.

В идеологии конфуцианской цивилизации путешествие (туризм) имеет поистине сакральный смысл, поскольку является универсальным методом познания (Аао) окружающего мира. Философское содержание путешествия в первую очередь раскрывает культурно-историческое единство того или иного региона, объективно демонстрирует тесную взаимосвязь людей с окружающим миром, убедительно доказывает, что человек не является случайным явлением в мире, а представляет собой его неотъемлемую часть. В данной связи особенностью регионального туризма в Восточной Азии совершенно явственно выступает мировоззренческая составляющая, главный смысл которой восходит к формированию интегрированного взгляда на политику, экономику и культуру региона, его духовную особость, т. е. специфическое философское осознание сущности развития восточноазиатской части мира (Suzuki, 2013: 5). С учетом активной региональной интеграции Восточная Азия объективно развивается в рамках модели, предложенной Китаем. Будучи неоспоримым лидером Восточноазиатского региона, Пекин явно стремится к формированию целостной системы «множества путей», составляющих с древнейших времен, по сути дела, единое пространство под названием Великий шелковый путь. Именно он создает единый восточноазиатский туристический рынок, что придает мощный импульс для уверенного становления евразийской региональной интеграции. Вряд ли стоит сомневаться, что Российская Федерация воспользуется представившимися возможностями и активно включится в евразийский интеграционный процесс, оказывая на его становление собственное эффективное влияние.

\section{ЗАКАЮЧЕНИЕ}

Резюмируя, можно констатировать, что восточноазиатский туризм отображает природное и культурное многообразие стран региона, их экономические достижения, стремление сохранить тысячелетнее наследие. Туризм - это глубокое культурное явление в жизни местных сообществ, ставшее серьезным фактором социального равновесия, взаимопонимания между народами Восточной Азии и их межличностного общения. Именно туризм стал в регионе важным каналом ознакомления с достижениями человеческого духа, уважения человеческих достоинств и индивидуальности, признания самобытности культур и моральных ценностей восточноазиатских наций. Тяга к путешествиям, потребность в дальнейшем развитии культуры и желание получать удовольствие от приобретенного знания породили в Восточной Азии весьма своеобразную индустрию. Восточноазиатский туризм, помимо всего прочего, стимулирует образование и научную деятельность, что позволяет сделать вывод о появлении в 
регионе нового потенциально важного направления исследований - философского осмысления сущности регионального культурного наследия и перспективы его дальнейшего развития.

\section{СПИСОК АИТЕРАТУРЫ / REFERENCES}

Chang-Hung Tao (2012) Huaqiao tourist activity in East Asia East Asia tourist research center. PRC: Shanghai daxue chubanshe. 104 p.

Chen, Y., Mak, B., McKercher, B. (2011) What Drives People to Travel. Integrating the Tourist Motivation Paradigms // Journal of China Tourism Research. № 7 (2). P. 120-136.

Furuyi, H. (2014) Zai Higashi Ajia Tyugokukei kakyo no kanko kozo [Tourist structures of connected with PRC overseas Chinese communities]. Tokyo : Toyo keizai syuppan. 21 р. (На яп. яз.).

Hoshino, S. (2014) Higashi Ajia kanko sangyo [Tourist industry]. Tokyo : Waseda daigaku kenkyukai. 34 р. (На яп. яз.).

Iwate, Y. (2014) Higashi Ajia chiiki kanko [Regional tourism in East Asia]. Japan : Nihon ryokogyo kyokai jyanaru. 103 р. (На яп. яз.).

Nakayama, J. (2013) Nihon kanko sangyo senryakutekina mitoshi [Strategic perspectives of Japanese tourist industry]. Tokyo : Keiyo daigaku syuppan. 25 р. (На яп. яз.).

Nishida, S. (2014) Kokusai kanko ni okeru seiji no eikyo [Political influence in international tourism]. Tokyo : Hitotsubashi daigaku kenkyu senta. 84 р. (На яп. яз.).

Sawada, K. (2014) Higashi Ajia chiiki togoka no ronri [The logic of regional integration in East Asia]. Tokyo : Meiji daigaku suppan. 22 р. (На яп. яз.).

Sharpley, R. (2012) Challenges of Economic Development through Tourism // International Journal of Tourism Research. № 4. P. 221-235.

Su-Hsin Lee (2014) Dongya lüxing de qüxiang he bianhua [The Trends and Changes of East Asian Tourism]. Taipei: Guojia Taiwan zhengchang daxue chubanshe. 46 р. (На кит. яз.).

Suzuki, H. (2013) Higashi Ajia kanko no tetsugaku [The Philosophy of East Asian Tourism]. Tokyo : Waseda daigaku chiiki kanko kenkyukai. 46 р. (На яп. яз.).

Vincent, S. (2014) Development of East Asian Tourism. Singapore : Hilton Worldwide Press. 36 p.

World Bank (2015 $\backslash 2016)$. Travel Trends Report. 40 p.

Zhang, X. (2014) Dongya qüyuxing lüxing tongyihua: fazhan qüxiang de fenxi [Analysis on the development trend of the regional tourism integration in East Asia]. Wuhan : Jianghai daxue chubanshe. 165 р. (На кит. яз.).

Аата поступления: 09.01.2016 2.

\section{EAST ASIAN INTEGRATION IN THE SPHERE OF INTERNATIONAL TOURISM \\ V. I. BALAKIN \\ MOSCOW UNIVERSITY FOR THE HUMANITIES}

International tourism as a form of regional integration takes a specific place in numerous research projects which analyse complicated processes of modern social development. That fully relates to the East Asian region where the dialectics of relations between local governments has a compound historical heritage. Experts consider international tourism in East Asia to be a very serious integration factor assisting to overcome old regional contradictions. The article makes an attempt to present the real state and prospects of integration space development in South East Asia, including the sphere of international tourism.

East Asian market of tourist services is one of the most competitive in the world. Its specific feature is that it creates trends that later on appear on the global level. Practically all countries in East Asia lay emphasis on internal and entrance kinds of tourism, thus developing the countries' national infrastructure and making significant contributions to local budgets. Internal tourism is based on visiting historic sites, monuments of ancient culture, on pilgrimage missions connected with religious traditions, while entrance tourism of foreigners is orientated mainly to receiving cheap, highly quali- 
fied medical services within the framework of the programmes implying conducting complex diagnostics and treating complicated diseases.

In PRC they strongly believe that by uniting regional independent states it will be possible to create a common tourist industry which could stimulate the instilling of the single Confucian civilization ideas in people's consciousness. Recently Chinese authorities on all levels have started to advocate the so-called internationalization considering it to be an exclusively East Asian regional project as opposed to the Western concept of globalism.

East Asian tourism reflects the natural and cultural variety of countries in the region, their economic achievements, aspiration to preserve the thousand-year-old heritage. It is tourism in the region that has become an important channel of acquaintance with achievements of human spirit, respect for human virtues and individuality, acknowledgement of cultures' peculiarity and the moral values of East Asian nations. East Asian tourism stimulates education and scientific activity, which enables to comprehend the essence of regional cultural heritage and prospects of its further development in a philosophic manner.

Keywords: East Asia; integration; international tourism; regional contradictions; overseas Chinese communities

Submission date: 09.01.2016.

Балакин Вячеслав Иванович - кандидат юридических наук, доцент кафедры регионоведения факультета международных отношений и туризма Московского гуманитарного университета. Адрес: 111393 Москва, ул. Юности, д. 5. Тел.: +7 (499) 374-55-90. Эл. адрес: viacheslavbalakin@rambler.ru

Balakin Vyacheslav Ivanovich, Candidate of Law, Associate Professor, Department of Regional Studies, Faculty of International Relations and Tourism, Moscow University for the Humanities. Postal address: 5 Yunosti St., 111395 Moscow, Russian Federation. Tel.: +7 (499) 374-55-90. E-mail: viacheslavbalakin@rambler.ru 